\title{
Strategies for U. S. Firms to Better Penetrate Japanese Markets
}

\author{
Nobuaki Namiki \\ School of Business \& Public Administration \\ California State University \\ Sacramento, California
}

There has been much heated debate over Japanese trade barriers mainly because of huge and growing trade deficits with Japan. Until the late 1970's, many U.S. government officials, businessmen and academics have blamed tariff and non-tariff barriers imposed by the Japanese government. After intense negotiation with Japan, the U.S. government has been successful in reducing or eliminating legal barriers for many manufacturing goods and financial services. Also, in addition to the trade liberalization programs, the Japanese government has initiated capital liberalization programs so foreign companies can acquire Japanese companies to gain ready access to Japanese markets.

In spite of these programs and recent drastic appreciation of Japanese currency against the U.S. dollar, except for a few specific products, U.S. trade deficits with Japan have continued to increase. Quite simply, many American companies still have not succeded in penetrating the Japanese markets. Two explanations are offered for this phenomenon. First, some argue that the Japanese government, through various forms of assistance to private business and subtle legal restrictions, helps prevent foreign companies from entering Japanese markets [10]. Additionally, the unique Japanese culture is itself considered a non-tariff barrier against foreign companies [15]. For example, Japanese value long-term, personal, trusting business relationships, which are not easily established with American businessmen because of language barriers and cultural differences.

However, another barrier, not so well known but much more formidable than those mentioned above, also exists. This barrier is related to the unique economic environment-or more specifically, the market structure-in Japan. A distinctive feature of Japanese markets is the grouping of companies or interfirm relationships. Unlike the competitive market structures of the United States and other countries, powerful groups of companies in Japan, referred to as keiretsu or industrial groups, control nearly half of the Japanese economy. American companies without knowledge of such barriers and means to deal with them have considerable difficulties in entering Japanese markets. This article will explain why and how market-structure based barriers work against American

Journal of Business Strategies, Volume 5, Number 1 (Spring 1988) 
companies attempting to penetrate the Japanese market, and suggest strategies for U.S. companies in overcoming these barriers.

\section{The Market-Structure Based Barriers}

The essence of market-structured based barriers is related to the complex relationships established between companies within industrial groups, and between groups of companies. The interfirm relationships raise trade barriers by influencing Japanese companies' decision making processes, thereby binding their behavior patterns. As a consequence, their behavior or action patterns in conducting business or in competing in the markets are substantially different from those of American companies. There are basically three types of relationships: (1) relationships between a parts supplier, a manufacturer, and a distributor, with a single product line; (2) cooperative relationships between companies within a group; and (3) competition between groups of companies, or industrial groups. The following sections will describe the major characteristics of industrial groups and explain each type of interfirm relationship.

\section{Industrial Groups}

Until the end of the World War II, the Japanese economy was virtually controlled by the zaibatsu, ten family owned and controlled industrial and banking combines. They accounted for about one-third of incorporated business in Japan [8]. After the war, the Allied Occupation Force dissolved the zaibatsu in order to reduce the concentration in the economic sector and to promote democracy in Japan. However, these companies later regrouped, and the groups are now called keiretsu or industrial groups, without family control. Today, there are six industrial groups that were regrouped based on the old zaibatsu. They are Mitsui, Mitsubishi, Sumitomo, Fuji, Sanwa and Dai-Ichi Kangyo. The first three keiretsu are the direct successors of old zaibatsu, and the latter three are tied through their main banks and also successors of some former, smaller zaibatsu brethren [7].

An industrial group consists of many large firms plus numerous small-to medium-sized companies. Selected large companies are represented by their presidents in the group's president club, the overall policy making organ, and are called "member companies." The member companies are usually oligopolists in their respective markets. Their predecessor zaibatsu had tried to achieve an oligopolistic position in a wide range of industrial activities. As a result, few member companies in an industrial group are monopolists, and each industrial group includes almost every industry in Japan. There are twenty-three member companies participating in the president club in Mitsui Group, twenty-eight in Mitsubishi, and twenty-one in Sumitomo [17]. Each member company with its subsidiaries and related companies represents one broadly defined industry. Each keiretsu has only one member company representing each industry in order to ensure minimum competition and conflict within the industrial group. 
Unlike prewar zaibatsu whose companies were privately owned and controlled by the family owned holding company, ownership control is absent within an industrial group. However, there is a considerable coordination among companies within a group, through financial control, interlocking directorates and personal relations, in addition to the regular meetings of member companies' presidents at the group's presidents' club. Every industrial group includes the main bank and its related financial institutions which are usually considered the group's leaders and provide financing mainly to the companies within the group, and the trading company which conducts import and export transactions mainly for the group's companies. Though financing institutions are prohibited by law from owning more than ten percent of any company, the group's main bank, through provision of huge financial as well as management resources, has considerable influence over the member companies [4]. The companies usually accept the bank's management personnel who oversee them as the companies' top executives, thereby losing their management autonomy to, and allowing substantial control by, the main bank. It should be noted, however, that the influence of main banks over member companies has recently been somewhat reduced because of financial successes by many large Japanese companies.

Coordination within an industrial group is also enhanced by cross stockholdings and interlocking directorates. Companies within industrial groups hold their shares mutually, usually much less than ten percent each. However, a considerable portion of a company's stock is held by companies belonging to the industrial group. Nearly seventy percent of Japanese corporate shares are held by institutions $([11],[12])$.

Large Japanese firms belong to industrial groups because of the benefits from the association and of the high costs of not belonging to a group, in addition to the Japanese desire to belong to groups-often called "groupism," a cultural norm in Japan. The benefits are substantial, and include access to financial and capital markets through the main bank, access to export market and distribution channels, and improved corporate image/status. An industrial group also helps its member companies compete with those in different groups. Moreover, a group provides protection to those member companies with financial problems. Though bankruptcy rates for smaller firms are high in Japan, those for large firms are extremely low because of protection by industrial groups. There are only a few large companies, including such notables as Sony and Honda, which do not belong to industrial groups.

The six industrial groups explained above are sometimes called "financially linked" keiretsu or industrial groups. In addition, there are ten or so manufacturers' groups or enterprise keiretsu, each composed of one huge manufacturer and numerous parts suppliers, without the main bank. The examples are Toyota, Matsushita, Nissan, Tokyo Shibaura (Toshiba), and Hitachi Groups. Most of them participate in presidents' club of one financially linked keiretsu because of the benefits from the association mentioned above. Some of them participate 
in presidents' clubs of two financially linked groups, such as Nissan and Hitachi [13].

\section{Manufacturer-Distributor Relationships}

Japanese distribution channels are usually perceived as extremely complex, having many layers of wholesalers in the distribution structure. However, the nature of relationships between manufacturers and distribution channels in Japan differs greatly from that in the United States. In Japan, each distributor is a loyal and exclusive wholesaler for one manufacturer in each product category ([15], [18]). This is one of the reasons that many foreign companies have difficulty in obtaining distribution channels in Japan.

Large manufacturing companies (member companies) have for a long time expended tremendous effort and energy in developing and maintaining the exclusive distribution networks. Japanese manufacturers often own substantial stocks of their key distributors. Most manufacturers extend generous financing (or credit) to the wholesalers, and the wholesalers are also expected to provide their retailers with generous financing. Manufacturers are also expected to be responsible for unsold items; retailers can return unsold items and get full credit. In return, manufacturers expect their distributors to aggressively push their products and often to maintain retail prices at the same level in all classes of trade.

\section{Manufacturer-Parts Supplier Relationship}

Many American businessmen have claimed that large Japanese manufacturing companies tend to procure parts from other Japanese companies rather than from foreign companies. This tendency stems mainly from the large-sized manufacturers' substantial control over small-sized parts suppliers, and the resulting benefits for the manufacturers. They have established key large-sized suppliers as their own subsidiaries, often with substantial ownership and financial control. In turn, these key subsidiaries have developed their own network of smaller-sized parts suppliers and subcontractors. And these smaller-sized parts suppliers and subcontractors have developed their own network of even smaller-sized parts suppliers and subcontractors. In other words, they have developed a pyramid-type subcontracting structure which has a hierarchy of parts suppliers. The relationship of a company with lower-level hierarchy to that with higher-level hierarchy is exclusive, i.e., captive of the higher-level hierarchy company.

This industrial structure, of course, tremendously benefits big business. Because of the structure, most large manufacturing firms do not have incentives to be integrated into labor-intensive, low-productivity parts manufacturing, and instead, procure parts at minimal cost from substantial numbers of subcontractors who usually pay low wages. The Japanese economy is characterized as "dual structure" because large-sized companies co-exist with numerous small 
companies and there are wide gaps in productivity and wages. Employees at smaller companies receive around $35 \%$ to $45 \%$ lower wages than workers at big companies, get considerably fewer fringe benefits, and enjoy no lifetime employment privilege [2]. In 1971, almost sixty percent of small and medium-sized manufacturing companies in Japan were classified as subcontractors [14]. Moreover, because of the dependency of subcontractors on their manufacturer, the manufacturing companies can depend on the subcontractors for quick delivery of these low-cost, high quality parts. An example of the close working relationship can be found in the kanban or "Just-In-Time" inventory system employed by Toyota Motor Company.

\section{Across-Industry Cooperation Within An Industrial Group}

Member companies within an industrial group conduct substantial economic transactions among themselves, often through their group's trading company. It should be noted that this is an across-industry cooperation within an industrial group, while the previous section deals with a member company relationship with its suppliers and subcontractors within its respective industry. The intra-group buying and selling originated in the prewar zaibatsu, when the family-owned holding company encouraged business between the subsidiaries mainly through the trading company [7]. Though the business conducted between member companies within a group has been much less than in the prewar zaibatsu, member companies have still preferred to do business with their group's members and their related companies.

However, the degree of cohesiveness among member companies within a group differs considerably from one group to others. Nearly three-fourths of the managers in Mitsui, Mitsubishi and Sumitomo Groups, the three direct successors of the prewar zaibatsu, expressed their pride in belonging to their respective groups. On the other hand, only half of managers in Sanwa Group, a smaller industrial group tied through the main bank-Sanwa Bank-expressed this pride. Also, about two-thirds to three-fourths of managers in the three groups expressed their wish primarily to buy commodities produced by their member companies of the same group, compared to only about one-third of those in Sanwa Group [13].

\section{Competition Between Industrial Groups}

While there is strong cooperation within an industrial group, competition exists between industrial groups. It should be noted that "competition" in the Japanese context is different from that in American or Western context. In the United States, competition exists between individual companies with the same or similar product lines or in the same industry. In Japan, competition exists not only between individual companies with the same product line, but also between companies (with different product lines) belonging to different indus" trial groups. The major driving force for competition in markets is the desire to 
improve status and prestige of the industrial group. In Japan, where a cooperative rather than individualistic business philosophy prevails, competition means intergroup rivalry for status and prestige [8]. A larger, stronger member company helps improve the industrial group's prestige and image. Also, a group's status of image is considered higher if it includes a larger number of big, growing companies, and represents larger numbers of industries, compared to other industrial groups. An industrial group's member companies have strong needs to expand internally, add new product divisions, or establish new subsidiaries.

Therefore, competition among Japanese companies in Japanese and overseas markets tends to center on capturing market share or increasing sales volume, sometimes even at the sacrifice of short-term profits. Since substantial blocks of shares are held by companies in the industrial group, a company can forego short-term profits when it needs to aggressively compete with companies with the same product line in different industrial groups. Also, the main bank in the group can help the company with financing, the trading company with marketing, and other companies in the group with capital infusion and other assistance, when needed. A challenge by a company against those in different groups can lead to competition between industrial groups, and can escalate to "excessive competition" whereby rival groups lower and continue to maintain prices below production costs [8].

\section{Strategies to Penetrate the Japanese Market-Structure Based Barriers}

The structure of Japanese markets is substantially different from that of markets in the United States and other Western countries. It is essential for American businesspeople to understand the Japanese market structure and, based on that knowledge, to position themselves in the market. The following strategies and approaches are recommended to American executives preparing to enter the Japanese market.

\section{Assessing Competitors' Responses in the Japanese Market}

When considering entry into the Japanese market, it is important to assess accurately the likely responses of established Japanese competitors. Intensity of resistance or response depends largely on the number of participants in the market, their sizes and stakes in the market, and more important, the commitment or policy of the involved industrial groups to the market.

When a foreign company enters a market that is represented by many large-sized member companies of industrial groups, it can expect formidable resistance. Member companies of an industrial group are the "flagships" of the group; the group's status and prestige depend largely on these companies' growth and performance. Therefore, other member companies and the related 
companies in the group directly and indirectly support a member company facing substantial threats from a foreign company. This competition, then, is not only with the member companies in the industry but also with the other companies in the industrial groups. Member companies threatened with substantial market penetration by foreign companies can raise the entry barriers through many means, such as financial and other assistance from the main bank and other member companies, cooperation from the distribution channels and the parts suppliers, and even assistance from the Japanese government. One of the major reasons why some American and other foreign companies have failed in the Japanese market is that they have underestimated Japanese responses in the market.

Another indicator of the intensity of the resistance is the Japanese government's industrial policy. The Japanese government, notably the Ministry of International Trade and Industry (MITI), has promoted development of certain industries through "administrative guidance," subsidies, and tax incentives [9]. Industrial groups tend to make their resource allocation decisions based on governmental policy or guidance. In the industries targeted for development by the government, competition is fierce even for Japanese companies. For example, under governmental guidance, all the industrial groups have been supporting development of computer and semiconductor companies within their groups. In many industrial groups, some member companies have formed joint ventures in order to combine their technical and other resources to develop and compete with other companies in different industrial groups. The result in the semiconductor industry is overcapacity (and overproduction) and "excessive competition" by Japanese companies in the Japanese as well as world markets. Competition in the computer industry is similar; all industrial groups have been developing their own computer companies, some of which have been challenging, and gradually gaining ground against, the market leader, I.B.M. Two of I.B.M.'s responses to the increased competition are to closely monitor government policy on the market and to have a voice in the policymaking process by joining industry associations and government advisory groups [3]. Therefore, it is essential for American companies to monitor policies of the Japanese government and industrial groups on the industry.

Many large-sized American and other foreign companies have been successfully exporting to or operating in Japan. Examples are I.B.M., Esso, and Nestle. The companies tend to possess superior technologies, new products, or brand identification to highly differentiate themselves from Japanese companies, thereby avoiding head-on competition in the markets. Also, these companies tend to possess considerable capital, technology, and managerial resources [16]. Moreover, in some cases, industrial groups have "accepted" the foreign companies because the group's member companies have no capability to produce the foreign companies' products or similar products, yet need their products. However, foreign companies without such capital, technology, and managerial 
resources would have considerable difficulties in penetrating and succeeding in the Japanese market. These companies seek a niche in the market. The strategy to carving a niche in the Japanese market, however, is considerably different from that in the U. S. market.

\section{Seeking a "Niche" or "Void" in Industrial Groups}

The approach is to seek a "niche" in an industrial group. Though all industrial groups attempt to be the leaders or oligopolists in each industry or market, some groups have weaker positions than others. In some cases, an industrial group supports a marginal company to maintain presence in the industry in order to sustain the group's image and prestige. Moreover, not every group is represented in each industry. The largest three, Mitsui, Mitsubishi, and Sumitomo Groups, represent a broader range of industries than the others. Some industries are dominated by a few groups because of group history. The prewar zaibatsu had emphasized certain industries during their development stages. For example, the Mitsui zaibatsu controlled paper, coal, synthetic dyes and much of the foreign trade; the Mitsubishi zaibatsu controlled heavy industry, shipbuilding, marine transportation, and plate glass [1].

The differences in representation or strengths of industrial groups in markets present opportunities for the entry of foreign companies to Japanese markets. An industrial group with weak or no market position in an industry may even encourage foreign companies to "associate" with the group in order to compete with other companies in different industrial groups. The opportunity is presented due to intense intergroup rivalry for status and prestige. The association benefits both the industrial group and the foreign company.

In selling an industrial product to Japanese companies, search for an industrial group without a company producing the product. Because the industrial group needs to "import" the industrial goods from other industrial group's companies, companies in that group may be much more inclined to buy from foreign companies than those in groups which have their own producers, given superior services, technologies, and other available amenities. Also, companies in an industrial group which includes a company that is producing the industrial product but is only marginally competitive in the market due to obsolete technologies, poor services, or other controllable reasons, may be willing to buy from outsiders.

For consumer products, the wholesalers or distributors which belong to an industrial group without companies manufacturing the products may be more likely to carry foreign goods. Also, an industrial group usually has large-sized department store chains that mainly distribute its group member companies' products. Therefore, in order to identify an established distribution channel that is willing to carry foreign products, search for a niche or void in one of Japan's industrial groups. 
Since the larger industrial groups, Mitsui, Mitsubishi, and Sumitomo, represent a wider range of industries, there would be a higher chance of associating with the other smaller industrial groups, such as Fuji, Sanwa, and Dai-Ichi Kangyo. However, as mentioned previously, there are more cohesive, cooperative relationships among companies in the larger industrial groups than among those in the smaller industrial groups.

\section{Investigating the Interfirm Relationships}

So far, the above recommendations are made mainly based on "generic" behavior patterns by Japanese companies that are influenced by the presence of industrial groups and the cooperative nature of interfirm relationships in Japan. However, the degree of cooperation or the nature of the relationship between companies may differ greatly depending on specific ties between companies, industry conditions, and industrial groups. Investigation of the nature of interfirm relationships in the specific industry or market is important because the knowledge can help:

1. identify Japanese companies which are more likely to buy foreign products or carry the products in their distribution channels, within the specific industry;

2. identify with what objective Japanese companies conduct business or compete in the market;

3. develop and nurture relationships with Japanese parts suppliers or distribution channels, when a foreign company decides to make direct investment in Japan; and

4. develop and nurture business relationships with Japanese companies in the market or in related industries.

The basic web of relationships can be based on familial ties, marital ties, personal friendships, long-term business relationships, or other factors, between top managers of companies. These relationships can be reinforced by interlocking directorates, cross stockholdings, and exchange of management personnel between companies. In some cases, relationships among related companies are so strong that it is virtually impossible for a foreign company to supply parts or to conduct business with the Japanese target company. For example, the Toyota Motor Company procures most parts from firms whose presidents are from the Toyoda family, the founding family of the company [6]. In other cases, the relationships are weak. Firms have business, but less cooperative, relationships due to a short history of business transactions between the companies. Newer companies such as Honda, tend to have loose ties with other companies. The relationship may also be weak in a changing, volatile business. In these 
cases, a Japanese company may be much more receptive to dealing with foreign companies.

Moreover, the investigation of these relationships can lead to better understanding of a Japanese company's behavior patterns, as well as its motivations and expectations in conducting business. Unlike a U. S. company, where more business decisions are made in "rational" fashion, Japanese companies may behave irrationally (in an American or Western sense) mainly because of their intricate web of relationships with other companies. For example, it may be judged "prudent" by Japanese parts suppliers to help their customers compete in the growing market by reducing their prices for their parts below market prices, based on the close relationships, such as marital ties, and the expectations that they will benefit in the long-run. It would be understandable that, without knowing the nature of interfirm relationships, misunderstandings and resulting mistrust would develop between Japanese and American companies conducting business together. This is one of the major reasons why many joint ventures between Japanese and American companies have failed in the past. Therefore, it is essential for U. S. companies conducting business with Japanese companies or operating in Japan to understand what kinds of behavior are expected and required. Also, for American companies making direct foreign investment in Japan, it is important to know the expected behavior in developing parts suppliers' networks and distribution channels, as well as developing and nurturing relationships with other entities, such as banks and trading companies, in order to facilitate smoother business transactions in Japan.

\section{Conclusion}

The Japanese market is substantially different from that in the United States or other Western countries in many aspects, of which the major differences stem not only from culture and government policy, but also unique market structure. The market-structure based barrier is a formidable obstacle against American companies entering Japanese markets mainly due to lack of experience with this type of trade barrier. Better understanding of the Japanese market structure can greatly help U. S. firms overcome the barrier and, moreover, formulate and implement viable strategies to enter Japanese markets. Armed with this knowledge, they must make renewed efforts to enter the large and potentially very profitable markets of Japan.

\section{References}

1. Bieda, K. The Structure and Operation of the Japanese Economy. New York, NY: John Wiley and Sons Australasia Pty., Ltd. (1970).

2. Broadbridge, S. Industrial Dualism in Japan: A Problem of Economic Growth and Structural Change. Chicago, IL: Aldine Publishing Company (1966). 
3. Browning, E. S. "Lobbying in Japan So Daunts U. S. Firms That Few Even Try." Wall Street Journal. April 1, 1986, pp. 1, 19.

4. Caves, R. E. and Uekusa, M. "Industrial Organization." In H. Patrick and H. Rosovsky (eds.), Asia's New Giant: How the Japanese Economy Works. Washington, DC: The Brookings Institution (1976), pp. 461-523.

5. Czinkta, M. R. "Distribution in Japan: Problems and Changes." Columbia Journal of World Business, Vol. 20, No. 3 (Fall 1985), pp. 65-71.

6. "Frugal, Reclusive Commanders Of An Industrial Army." Business Week, November 4,1985 , pp. $45-46$.

7. Hadley, E. M. Antitrust in Japan. Princeton, NJ: Princeton University Press (1970).

8. Haitani, K. The Japanese Economic System. Lexington, MA: Lexington Books (1976).

9. Johnson, C. M.I.T.I. and the Japanese Miracle: The Growth of Industrial Polkcy, 1925-1975. Stanford, CA: Stanford University Press (1982).

10. Johnson, C. "The 'Internationalization' of the Japanese Economy." California Management Review, Vol. 15, No. 3 (Spring 1983), pp. 5-26.

11. Nishiyama, T. "The Structure of Managerial Control: Who Owns and Controls Japanese Business?" In K. Sato and Y. Hoshino (eds.), The Anatomy of Japanese Business. Armonk, NY: M. E. Sharpe, Inc. (1984), pp. 123-163.

12. Ohmae, K. The Mind of the Strategist: The Art of Japanese Business. New York, NY: McGraw-Hill (1982).

13. Sasaki, N. Management and Industrial Structure in Japan. New York, NY: Pergamon Press (1981).

14. Small and Medium Enterprises Agency. Chusho Kigyo Hakusho, Showa 50-nen ban (White Paper on Small and Medium Enterprises, 1975). Tokyo, Japan: Ministry of Finance, Printing Bureau (1975).

15. Woronoff, J. World Trade War. New York, NY: Praeger (1984).

16. Wright, R. W. "Joint Venture Problems in Japan." Columbia Journal of World Business, Vol. 14, No. 1 (Spring 1979), pp. 25-31.

17. Yoshihara, K. Sogo Sosha: The Vanguard of the Japanese Economy. Oxford, UK: Oxford University Press (1982).

18. Zimmerman, M. How to Do Business With the Japanese. New York, NY: Random House (1985). 